This item was submitted to Loughborough's Research Repository by the author.

Items in Figshare are protected by copyright, with all rights reserved, unless otherwise indicated.

\title{
How many days of pedometer monitoring predict monthly ambulatory activity
} in adults?

PLEASE CITE THE PUBLISHED VERSION

http://dx.doi.org/10.1249/MSS.0b013e318177eb96

PUBLISHER

(c) American College of Sports Medicine

VERSION

AM (Accepted Manuscript)

LICENCE

CC BY-NC-ND 4.0

\section{REPOSITORY RECORD}

Clemes, Stacy A., and Paula L. Griffiths. 2019. "How Many Days of Pedometer Monitoring Predict Monthly Ambulatory Activity in Adults?”. figshare. https://hdl.handle.net/2134/15572. 
This item was submitted to Loughborough's Institutional Repository (https://dspace.lboro.ac.uk/) by the author and is made available under the following Creative Commons Licence conditions.

\section{creative
commons}

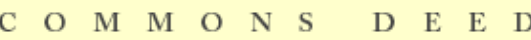

Attribution-NonCommercial-NoDerivs 2.5

You are free:

- to copy, distribute, display, and perform the work

Under the following conditions:

Attribution. You must attribute the work in the manner specified b the author or licensor.

Noncommercial. You may not use this work for commercial purposes.

No Derivative Works. You may not alter, transform, or build upon this work.

- For any reuse or distribution, you must make clear to others the license terms of this work.

- Any of these conditions can be waived if you get permission from the copyright holder.

Your fair use and other rights are in no way affected by the above.

This is a human-readable summary of the Leqal Code (the full license).

\section{Disclaimer 만}

For the full text of this licence, please go to: http://creativecommons.org/licenses/by-nc-nd/2.5/ 
How many days of pedometer monitoring predict monthly ambulatory activity in adults?

Stacy A Clemes and Paula L Griffiths

Institutional affiliation of both authors:

Department of Human Sciences, Loughborough University

Corresponding Author: Dr Stacy A Clemes

\section{Corresponding Author Address:}

Department of Human Sciences

Loughborough University

Leicestershire

LE11 3TU

UK

Telephone: $\quad+441509228170$

Fax: $\quad+441509223940$

Email: $\quad$ S.A.Clemes@lboro.ac.uk

Running title:

Prediction of monthly activity in adults

Paper In Press - Med Sci Sports Exerc 


\begin{abstract}
Purpose: To determine how many days of pedometer monitoring are necessary to estimate monthly ambulatory activity in adults.

Methods: 212 adults (64\% female, age $=38.3 \pm 13.3$ years, $B M I=27.9 \pm 5.3 \mathrm{~kg} / \mathrm{m}^{2}$ ) wore a pedometer (SW-200) for 28 consecutive days. 76.4\% were randomly allocated to a reliability group while the remainder $(\mathrm{n}=50)$ comprised a confirmation group. Mean step counts calculated over the 28-day period served as the criterion. Using the reliability group, intra-class correlations (ICCs) were computed for the entire 4 week period, for 3, 2 and 1 weeks, and for different combinations of any 6, 5, 4, 3 and 2 days. The reliability of the recommended time frame was tested in the confirmation group using regression analysis.
\end{abstract}

Results: In the reliability group, the ICC for any single given day was 0.41 . All combinations including 6 days or more had ICCs above 0.80 . The inclusion of participant characteristics into a regression, alongside mean steps reported during 1 week of monitoring, failed to strengthen the prediction. When tested in the confirmation group, there was a significant relationship between mean step counts calculated from the first week of monitoring and the criterion (adjusted $\mathrm{R}^{2}=0.91, \mathrm{p}<0.001$ ).

Conclusion: It is recommended that researchers collect pedometer data over a 7-day period for a reliable estimate of monthly activity in adults. A 7-day period is recommended, as opposed to 6 days (where ICCs were $>0.80$ ) because: 1 ) step counts are characteristically lower on a Sunday, thus for a reliable estimate of habitual activity, Sunday activity should always be included, and 2) in the event of missing data (1 day), data collected on six days will remain sufficiently reliable to estimate mean monthly activity.

Keywords: habitual activity, objective assessment, age, gender, BMI, reliability 


\section{INTRODUCTION}

Paragraph number 1 Pedometers are increasingly being used as a surveillance tool to objectively assess ambulatory activity levels and patterns in different populations. They provide an inexpensive, accurate and reliable, objective measure of ambulatory activity by counting the number of steps taken per day, enabling the accumulative measurement of occupational, leisure time and household activity, along with activity required for everyday transportation (12).

Paragraph number 2 Research assessing physical activity in a given population is typically interested in quantifying a person's usual or habitual activity level (2). According to Felton et al. (10) there is a need to establish the relative stability of pedometer-determined activity behaviour in a free-living sample. Such an exercise would be valuable as it will enable the identification of optimal monitoring frames necessary to determine a stable index of habitual activity (10). Earlier research has shown that day-to-day fluctuations in pedometer-determined ambulatory activity are not random and can in part be explained by real life fluctuations in behaviour caused by for example, the day of the week, participation in sports/exercise, and attendance at work (24). Day-to-day variability in pedometerdetermined activity may also be increased by factors beyond the control of the researcher, such as bad weather, and participant injury or sickness (2). In addition, seasonal changes in ambulatory activity have also been reported $(11,24)$. The identification of optimal monitoring frames required to estimate habitual activity will have important consequences regarding research design.

Paragraph number 3 The most appropriate monitoring frame to estimate habitual ambulatory activity of a healthy, free-living, adult sample is currently unknown, time frames used in the literature in recent pedometer surveillance studies have included four (28) and five (5) days, one week $(4,12,14,20,22,26)$, four weeks $(7,8)$, and one year (24). When considering research design, a balance has to be met between ensuring the monitoring period is sufficient to reliably estimate habitual behaviour without producing unnecessary participant burden. According to Baranowski and de Moor (2) respondent burden is the primary barrier to recording or assessing physical activity over many days. When considering participant burden, it is therefore necessary to establish a relatively short monitoring frame that can be used practically to study trends in behaviour change (10). Length of monitoring frame therefore has important implications for study design, most obviously to minimise both surveillance costs and respondent burden (10), while not limiting reliability. 
Paragraph number 4 To date, little research has investigated the stability of pedometer-determined activity data over defined periods of time and only a few studies have investigated the number of days required to estimate activity over pre-defined time periods, with these studies being limited to the estimation of weekly ambulatory activity (10,25). Tudor-Locke et al. (25) for example, reported that a minimum of three days of monitoring were necessary to achieve an intra-class correlation (ICC) of at least 0.8, and concluded from this research that three days of monitoring can provide a sufficient estimate of weekly activity in adults. These findings have recently been supported by Felton et al. (10), who also observed that three days of monitoring are necessary to estimate weekly activity in college women. In their study, Tudor-Locke et al. (25) caution that their findings only apply to the reliable estimate of weekly activity and no longer, and they highlight the possibility of continuing with this line of inquiry by investigating how many days of pedometer monitoring represent one month, a season, or even up to one year.

Paragraph number 5 To the authors knowledge, no studies have been conducted to ascertain how many days of pedometer monitoring are necessary to reliably estimate activity assessed over a longer duration than one week, despite it being commonly considered that the longer the monitoring frame, the greater the likelihood of determining habitual activity. The aim of the current study therefore was to continue the line of inquiry applied by Tudor-Locke et al. (25) and Felton et al. (10) by investigating the number of days necessary to reliably estimate monthly ambulatory activity in free-living adults. A secondary aim was to conduct some exploratory analyses to determine whether the number of days of pedometer monitoring required to predict monthly ambulatory activity differ when participants are grouped according to their gender, body mass index (BMI) and age.

\section{METHODS}

Paragraph number 6 The data set used in the current article has been previously published (8). The aim of the initial study, summarised below, was to describe pedometer-determined activity levels and patterns in a sample of normal weight, overweight and obese adults, over a period of four weeks. The present study examines how many days of pedometer monitoring are necessary in order to obtain adequate estimates of mean monthly pedometer-determined steps per day.

Paragraph number 7 The initial study conducted using this dataset received ethical approval from the Loughborough University Ethical Advisory Committee. 


\section{Participants and procedures}

Paragraph number 8 During January through to March in 2006, 254 participants from the East Midlands region in the UK were recruited to participate in a study that described activity levels and patterns of normal weight, overweight and obese adults over a four-week period. Participants were recruited via word of mouth and through advertisements placed in local media. Participants were recruited using a sampling frame that was developed to achieve an equal spread of individuals across the age range of 18 to 65 years. The sampling frame also ensured that, at the study outset, the sample contained similar numbers of individuals classified as either normal weight (BMI $<25 \mathrm{~kg} / \mathrm{m}^{2}$ ), overweight (BMI 25-29.9 kg/m²) or obese (BMI $\left.\geq 30 \mathrm{~kg} / \mathrm{m}^{2}\right)$ (27).

Paragraph number 9 A health screen completed at baseline confirmed that participants were all in good general health and none had any physical illnesses or disabilities that might affect their normal daily routine. Participants were informed about the purpose of the study, they received written and oral information about the study protocol and provided written informed consent.

Paragraph number 10 All participants were issued with a Digi-Walker SW-200 pedometer (New Lifestyles, Inc., Lees Summit, MO) and daily step log. This pedometer has been shown to accurately detect steps taken in both free-living conditions (16) and under controlled laboratory conditions using normal weight $(9,13,17)$, overweight and obese (21) individuals. Participants were instructed to wear the pedometer throughout waking hours for a period of four weeks, only removing when either bathing, showering or swimming. The appropriate position to wear the pedometer, on the waist band in-line with the midline of the thigh, was shown to participants at the outset. Pedometer accuracy was confirmed with each participant upon issue by means of a 20 step test (acceptance criteria: plus/minus two steps). Each night before going to bed participants recorded the number of steps displayed in their log, they were then requested to reset the pedometer ready for the following day.

Paragraph number 11 All participants were encouraged not to make any changes to their typical daily routine of work and leisure activity. Upon finishing the study all completed a brief post-study questionnaire enquiring whether they had suffered from any ill health, not worn the pedometer for a full day, or made any changes to their normal routine, diet, or general activity levels during the study period. 
Paragraph number 12 At the study outset body mass $(\mathrm{kg})$ and height $(\mathrm{cm})$ were directly measured without shoes using electronic weighing scales (Tanita UK Ltd) and a wall-mounted stadiometer (Seca UK) prior to the monitoring period. BMI was calculated as $\mathrm{kg} / \mathrm{m}^{2}$.

Paragraph number 13 Of the 254 participants starting the study, two were lost at follow-up. The 252 participants who completed the study reported, on the post-study questionnaire, no changes to their daily routine occurring throughout the four-week monitoring period. Of the 252 participants who completed the four-week study, 212 had 28 complete days of valid pedometer data, i.e. these participants had no missing pedometer data. The analyses presented in the current paper were therefore conducted using the data collected from these 212 participants. Independent samples t-tests were conducted to test for differences between the 212 participants providing 28-days of pedometer data and those participants discarded from the analyses described in this paper. No significant differences were observed between these two groups of participants in terms of mean daily step counts (212 participants with 28-days of data $=9263 \pm 3016$ steps/day versus 40 participants with missing data $=8868 \pm 3605$ steps/day, $\mathrm{t}=0.75, \mathrm{p}>0.05$ ). In addition, using $\mathrm{t}$-tests and chi-squared statistics it was established that the participants with 28-days of data did not differ in terms of gender distribution, age, height, weight, and BMI when compared with the 40 participants with missing data (all p>0.05). The sample used in the analyses reported herein consisted of 135 women (age $=37.3 \pm 13.6$ years, BMI $=27.9 \pm 5.8 \mathrm{~kg} / \mathrm{m}^{2}$, mean daily steps $=9454 \pm 3086)$ and 77 men $\left(\right.$ age $=39.9 \pm 12.6$ years, BMI $=27.8 \pm 4.3 \mathrm{~kg} / \mathrm{m}^{2}$, mean daily steps $=8930 \pm 2877)$. Independent samples t-tests revealed that there were no gender differences in terms of age, BMI or mean step counts reported over the four-week study, therefore males and females were combined into one group for the purposes of the analyses described in the current paper. Using participants' postcode to characterise the socio-economic status (SES) of the area in which they reside, it was observed that the sample used in the analyses came from neighbourhoods where unemployment ranged from $0.8 \%$ to $7.2 \%$, relative to the national average of $3.4 \%$, and the percentage of people in good health, in these neighbourhoods, ranged from $50 \%$ to $83 \%$, relative to the national average of $68.8 \%(15)$.

\section{Statistical analyses}

Paragraph number 14 Statistical analyses were conducted using SPSS for Windows version 15. Mean step counts were calculated over the four-week period for the sample as a whole. In addition, mean step counts reported on each specific day of the week were calculated using the four sets of data available for each day of the week. Using this data a repeated-measures ANOVA with Bonferroni 
corrected post hoc comparisons were applied to test whether mean step counts differed between days. The sample were then randomly assigned (using SPSS Random Sample function) to either a reliability analysis group or to a confirmation group. $76.4 \%(n=162)$ of participants were randomly allocated to the reliability analysis group while $23.6 \%(n=50)$ were randomly allocated to the confirmation group. Independent samples t tests were conducted to test for differences in age, BMI, and mean daily step counts between these two groups. The initial analyses conducted, to answer the research question 'how many days of pedometer monitoring are needed to reliably estimate monthly habitual activity, measured in terms of steps/day’ were performed using data from the reliability analysis group.

Paragraph number 15 A series of intra-class correlations (ICC) were computed, for the reliability group, to address the research question. ICCs estimate the consistency of data collected over multiple days, providing a measure of intra-individual variability (2). Data sets containing multiple days of pedometer data are regarded as appropriate for analysis using ICCs (25). ICCs were calculated for the entire four week period, for a three week period (using the first three weeks of monitoring), a two week period (using the first two weeks of monitoring), and a one week period (using the first week of monitoring). As it is logistically simpler to measure daily step counts from participants over a defined number of consecutive days/weeks, only consecutive days/weeks of step count data were used in the ICCs, when determining the reliability of step count data collected over a period of one week or longer. In addition however, ICCs were calculated for different combinations of any 6, 5, 4, 3 and 2 days, using data from the first week of monitoring, to make conclusions about combining data from nonconsecutive days, as occurs in datasets characterised by missing data. ICCs for multiple days were calculated using the following formula:

$$
I C C=\frac{\sigma_{s}^{2}}{\sigma_{s}^{2}+\left(\sigma_{e}^{2} / n\right)}
$$

Where $\sigma_{\mathrm{s}}{ }^{2}$ is the between subject variance, $\sigma_{\mathrm{e}}{ }^{2}$ is the within subject variance, and $n$ is the number of days of pedometer monitoring (2). Single day ICCs were also calculated using the following formula from Baranowski and de Moor (2).

$$
I C C=\frac{\sigma_{s}^{2}}{\sigma_{s}^{2}+\sigma_{e}^{2}}
$$

As recommended by Baranowski and de Moor (2), an ICC of 0.8 was chosen as the cut-off for determining the minimum number of days required to reliably estimate four-weeks of habitual activity. 
According to Baranowski and de Moor (2), ICCs higher than 0.8 have little additional value in the ability to detect true relationships.

Paragraph number 16 Upon deciding how many days of pedometer monitoring are necessary to estimate mean monthly activity, based on the results of the ICC's, regression analyses were undertaken to confirm the initial assumptions. A stepwise linear regression was undertaken whereby mean step counts calculated over the four week period for the reliability sample $(n=162)$ served as the criterion, with mean step counts calculated over the recommended number of days (based on the results of the ICC), along with participant demographic characteristics (age, height, BMI and gender) serving as the independent variables. These participant characteristics were included since differences in step counts have been previously reported between males and females (7,26), and between different BMI $(7,8,22,23,26)$ and age $(8,19,26)$ groups. Participant characteristics were included in the stepwise regression in order to determine whether the prediction of monthly habitual activity could be strengthened with their inclusion.

Paragraph number 17 Following confirmation of the estimated number of days required to predict monthly activity, a linear regression analysis was undertaken using data from the confirmation group (n = 50). Mean step counts calculated over the four week period for this group served as the criterion, with mean step counts calculated over the recommended number of days (based on the results of the ICC and regression analysis conducted on the reliability group, described above) serving as the independent variable. This additional analysis was undertaken to test the validity of our recommended time frame in a different sample.

\section{Exploratory analyses to investigate the number of days required to estimate habitual ambulatory activity in population sub-groups}

Paragraph number 18 Using the complete sample $(n=212)$, to improve statistical power, a series of exploratory ICCs were calculated to determine whether the number of days of pedometer monitoring required to predict monthly ambulatory activity differ when participants are grouped according to their gender, BMI and age. Whilst these characteristics were included in the regression analyses conducted using the reliability group to determine whether the prediction of monthly steps could be improved by considering demographic characteristics, this analysis tells us little about the consistency over time of daily step counts reported across participants with different characteristics. 


\section{RESULTS}

\section{Participants}

Paragraph number 19 The entire sample $(n=212)$ had a mean daily step count of $9263 \pm 3016$ steps/day. The reliability (64\% female) and confirmation (62\% female) groups did not differ significantly ( $>0.05$ ) in terms of their mean daily step count, calculated over the four week study, or in terms of their demographic characteristics (Table 1). In addition, mean step counts reported on each day of monitoring, over the 28 day period, did not differ significantly between groups (all p $>0.05$ ). Mean step counts reported on each day of the week, for the two groups and entire sample, are shown in Table 2. Step counts reported on a Sunday were significantly lower than those reported on all other days of the week following post hoc analyses in each of the two groups, and the sample as a whole (Table 2).

\section{Insert Tables 1 and 2 about here}

\section{Reliability analysis}

Paragraph number 20 Using the reliability group, the ICC for any single given day was 0.41. Any two-day combination ranged from 0.52 to 0.74 , any three-day combination ranged from 0.67 to 0.79 , any four-day combination ranged from 0.75 to 0.82 , and any five-day combination ranged from 0.79 to 0.84. All combinations of 6 days had ICCs above 0.80, while a seven day period (using the first week of monitoring) had an ICC of 0.86. Step count data collected over the first two and three week periods (of the four week study) had ICCs of over 0.90 (Table 3). From these analyses it is recommended that researchers collect pedometer data over a 7-day period for a reliable estimate of monthly habitual ambulatory activity in adults.

\section{Insert Table 3 about here}

Paragraph number 21 Using the recommendation of one week of monitoring, a linear stepwise regression analysis was undertaken to investigate whether the prediction of mean monthly activity can be improved by considering participant characteristics such as age, gender, height and BMI. For the regression analysis, mean step counts calculated over the four week period served as the criterion, whilst mean step counts calculated during the first week of monitoring were added as an independent variable, along with age, gender, height and BMI. In the first model of the regression, all variables were removed except for mean steps calculated for week 1 and this resulted in an adjusted $\mathrm{R}^{2}$ value of 0.83 
(standard error of estimate $[\mathrm{SEE}]=1191, \mathrm{p}<0.001$ ), in the second model produced the variable age was added and this resulted in an adjusted $\mathrm{R}^{2}$ value of $0.84(\mathrm{SEE}=1170, \mathrm{p}<0.001)$, a small improvement from model 1.

\section{Confirmation analysis}

Paragraph number 22 The reliability of using step count data collected over a period of one week to estimate mean monthly activity was tested in the confirmation group. There was a highly significant relationship between mean step counts calculated from the first week of monitoring and the criterion (mean monthly step counts) (adjusted $\mathrm{R}^{2}=0.91$, $\mathrm{SEE}=992, \mathrm{p}<0.001$ ).

Exploratory analyses to investigate the number of days required to estimate habitual ambulatory activity in population sub-groups

Paragraph number 23 When categorised according to gender, it was observed that 5 days or more of pedometer monitoring are required in females $(n=135)$ to achieve an ICC of 0.8 , whereas in males $(n$ = 77) a minimum of 6 days of monitoring are required to reach an ICC of 0.8. When categorised according to BMI it was observed that a minimum of 7 days are required in the normal weight group (n =68), a minimum of 6 days are required in the overweight group ( $\mathrm{n}=79$ ), and a minimum of 5 days are required in the obese sample $(n=65)$ to reach ICCs of 0.8. When categorised according to age, a minimum of 6 days are required in 18 to 29 year olds $(n=68)$, a minimum of 4 days are required in 30 to 45 year olds $(n=78)$ and a minimum of 7 days are required in 46 to 65 year olds $(n=66)$ to achieve ICCs of 0.8 .

\section{DISCUSSION}

Paragraph number 24 The aim of the current study was to investigate the number of days of pedometer monitoring that are necessary to reliably estimate monthly ambulatory activity in healthy free-living adults. Based upon the current findings, it is recommended that researchers collect pedometer data over a 7-day period for a reliable estimate of monthly habitual ambulatory activity in healthy free-living adults. These findings have important implications for study design given that a primary goal of physical activity surveillance is to quantifying a person's usual or habitual activity level (2), whilst minimising surveillance costs and respondent burden (10). 
Paragraph number 25 There was a significant trend for activity to decrease on a Sunday in the sample studied, with the sample as a whole reducing their activity by approximately 1800 steps/day on a Sunday in comparison with all other days. Reductions in activity on a Sunday have been reported elsewhere $(3,6,7,10,24,25)$ and it therefore appears that this widely reported decline in activity on a Sunday is not random, and reflects an inherent characteristic of real life fluctuations in behaviour. It is recommended therefore that in order to reliably estimate monthly habitual ambulatory activity in adults that a Sunday should always be included in the monitoring period. This suggestion is particularly important when considering overweight and obese adults, since reductions in activity on a Sunday in these individuals have been shown to be particularly pronounced $(7,8)$. The Sunday fluctuation in steps is part of the reason we are recommending that pedometer data should be collected for a period of seven days, and not six (where ICCs were $>0.80$ ), to reliably estimate monthly activity. If data were only collected throughout Monday to Saturday, for example, this could overestimate monthly activity. A second reason for recommending seven days as opposed to six is that in the event of missing data (1 day), data collected on six days will remain sufficiently reliable to estimate mean monthly activity.

Paragraph number 26 A secondary aim of the current study was to conduct some exploratory analyses to determine whether the number of days of pedometer monitoring required to predict monthly ambulatory activity differ when participants are grouped according to their gender, BMI and age. The results of these analyses revealed that step count data appears to be slightly more variable in males when compared with females with ICC's above 0.8 being achieved with 6 days of monitoring for males and 5 days of monitoring in females. The consistency of the data also appeared to vary with BMI, with ICCs of 0.8 being achieved with 7 days of monitoring in adults classified as normal weight (BMI $<25$ $\mathrm{kg} / \mathrm{m}^{2}$ ), 6 days of monitoring in overweight participants (BMI $25-29 \mathrm{~kg} / \mathrm{m}^{2}$ ), and 5 days of monitoring in obese participants $\left(\mathrm{BMI} \geq 30 \mathrm{~kg} / \mathrm{m}^{2}\right)$. As overweight and obese adults have been found to have lower step counts than their normal weight counterparts $(7,8,22,23,26)$, and are considered to be more sedentary, it is not surprising that there is less variability between days of monitoring in these groups. Variations in the consistency of pedometer data were also observed among different age groups, with ICCs of 0.8 being achieved with 6 days of monitoring in 18 to 29 year olds, 4 days of monitoring in 30 to 45 year olds and 7 days of monitoring in 46 to 65 year olds. The relatively high consistency of pedometer data collected in the 30 to 45 year olds surveyed could be attributed to set routines dictated by work and/or family commitments in this group. In contrast, the greater variability observed in the 46 to 65 year olds surveyed could be attributed to a number of individuals (29\%) in this category being retired. The results of these additional analyses should be treated as preliminary, since it was not the 
primary aim of the study to investigate the consistency of pedometer data in the discrete groups described above, thus there is a risk that some groups may be under powered statistically. There is the additional risk that when making comparisons across several variables statistically significant associations may arise by chance alone. However it would be interesting for further research to extend this line of investigation into the variability of pedometer data among different sub-groups of healthy adults. It is worth noting however that from these exploratory analyses, even in the participant sub groups with the most variability (normal weight adults and 46 to 65 year olds), seven days of pedometer monitoring is sufficient to achieve ICCs of 0.8 , further strengthening the recommendation of collecting pedometer data over this time period for the reliable estimate of monthly habitual activity in free-living adults.

Paragraph number 27 Whilst preliminary, the exploratory analyses described previously do suggest that the consistency of pedometer data varies according to different participant characteristics, and it is understandable that the more variable a person's habitual activity, the more days of monitoring would be required to achieve an accurate estimate of usual activity. For example, in a study investigating pedometer reliability, over a seven day period, in a sample of youth (10 to 14 year olds) and postmenopausal women with type 2 diabetes, Strycker et al. (19) found that at least 5 days of pedometer data were needed in the youth sample, and that just 2 days of pedometer monitoring were needed in the sample of older women to obtain reliability coefficients of at least 0.8 . When comparing pedometer data collected over two separate seven-day periods, Felton et al.(10) observed an ICC of 0.72 between the two monitoring periods in free-living college women. In comparison, in a study looking at the consistency of physical activity in patients with chronic obstructive pulmonary disease, Schonhofer et al.(18) reported an ICC of 0.94 between two separate seven day monitoring periods.

Paragraph number 28 We must caution that in the current study we are only estimating monthly habitual activity, in a healthy free-living sample of adults between the age range of 18 to 65 years. A limitation of the current study is the fact that the conclusions drawn from this research are based upon the analyses of a self-selected sample, from one region in the UK, and it is recommended that the current findings are confirmed in additional samples/populations. This research could be extended, as initially recommended by Tudor-Locke et al. (25), to investigate further how many days/weeks of pedometer monitoring represent habitual activity in a season, or even year round activity. 
Paragraph number 29 In conclusion, based upon the current findings, it is recommended that researchers collect pedometer data over a 7-day period for a reliable estimate of monthly habitual ambulatory activity in healthy, free-living, adults. A number of pedometer studies have previously employed this time frame $(4,12,14,20,22,26)$ and it appears that data collected over a period of one week is reasonable in terms of limiting participant burden. The findings of the current study have methodological implications for researchers, epidemiologists, behavioural scientists, and health practitioners interested in physical activity, particularly ambulatory activity, surveillance since they show that monthly ambulatory activity can be reasonably understood with just seven days worth of monitoring. This is a significant issue given the current public health threat related to physical inactivity (1).

\section{ACKNOWLEDGMENTS}

We wish to thank Sarah Hamilton and Martin Lindley for their help with data entry.

\section{CONFLICTS OF INTEREST}

There are no perceived conflicts of interest associated with this research. The results of the present study do not constitute endorsement by ACSM.

\section{REFERENCES}

1. Allender S, Foster C, Scarborough P, Rayner M. The burden of physical activity-related ill health in the UK. J Epidemiol Community Health. 2007;61:344-8.

2. Baranowski T, de Moor C. How many days was that? Intra-individual variability and physical activity assessment. Res Q Exerc Sport. 2000;71:S74-8.

3. Bassett DR, Jr., Cureton AL, Ainsworth BE. Measurement of daily walking distancequestionnaire versus pedometer. Med Sci Sports Exerc. 2000;32:1018-23.

4. Bassett DR, Schneider PL, Huntington GE. Physical activity in an Old Order Amish community. Med Sci Sports Exerc. 2004;36:79-85.

5. Bennett GG, Wolin KY, Puleo E, Emmons KM. Pedometer-determined physical activity among multiethnic low-income housing residents. Med Sci Sports Exerc. 2006;38:768-73.

6. Cardon G, De Cocker K, De BourdeaudhuiJ I. Pedometer-determined physical activity in Belgian adults. In Proceedings of International Congress on Physical Activity and Public Health. Atlanta, Georgia, USA, pp. 84, 2006. 
7. Clemes SA, Griffiths PL, Hamilton SL. Four-week pedometer-determined activity patterns in normal weight and overweight UK adults. Int J Obes (Lond). 2007;31:261-6.

8. Clemes SA, Hamilton SL, Lindley MR. Four-week pedometer-determined activity patterns in normal weight, overweight and obese adults. Prev Med. 2008; In press.

9. Crouter SE, Schneider PL, Karabulut M, Bassett DR, Jr. Validity of 10 electronic pedometers for measuring steps, distance, and energy cost. Med Sci Sports Exerc. 2003;35:1455-60.

10. Felton GM, Tudor-Locke C, Burkett L. Reliability of pedometer-determined free-living physical activity data in college women. Res Q Exerc Sport. 2006;77:304-8.

11. Hamilton SL, Clemes SA, Griffiths P. UK adults exhibit higher step counts in summer compared to winter months. Annals of Human Biology. 2008; In Press.

12. Hornbuckle LM, Bassett DR, Jr., Thompson DL. Pedometer-determined walking and body composition variables in African-American women. Med Sci Sports Exerc. 2005;37:1069-74.

13. Le Masurier GC, Tudor-Locke C. Comparison of pedometer and accelerometer accuracy under controlled conditions. Med Sci Sports Exerc. 2003;35:867-71.

14. McCormack G, Giles-Corti B, Milligan R. Demographic and individual correlates of achieving 10,000 steps/day: use of pedometers in a population-based study. Health Promot J Austr. 2006;17:43-7.

15. National Statistics. Neighbourhood Statistics. Crown Copyright. http://neighbourhood.statistics.gov.uk/ assessed November 2007.

16. Schneider PL, Crouter SE, Bassett DR. Pedometer measures of free-living physical activity: comparison of 13 models. Med Sci Sports Exerc. 2004;36:331-5.

17. Schneider PL, Crouter SE, Lukajic O, Bassett DR, Jr. Accuracy and reliability of 10 pedometers for measuring steps over a 400-m walk. Med Sci Sports Exerc. 2003;35:1779-84.

18. Schonhofer B, Ardes P, Geibel M, Kohler D, Jones PW. Evaluation of a movement detector to measure daily activity in patients with chronic lung disease. Eur Respir J. 1997;10:2814-9.

19. Strycker LA, Duncan SC, Chaumeton NR, Duncan TE, Toobert DJ. Reliability of pedometer data in samples of youth and older women. Int J Behav Nutr Phys Act. 2007;4:4.

20. Swartz A, Strath S, Parker S, Miller N, Cieslik L. Ambulatory activity and body mass index in white and non-white older adults. J Phys Act Health. 2007;4:294-304.

21. Swartz AM, Bassett DR, Jr., Moore JB, Thompson DL, Strath SJ. Effects of body mass index on the accuracy of an electronic pedometer. Int J Sports Med. 2003;24:588-92.

22. Thompson DL, Rakow J, Perdue SM. Relationship between accumulated walking and body composition in middle-aged women. Med Sci Sports Exerc. 2004;36:911-4. 
23. Tudor-Locke C, Ainsworth BE, Whitt MC, Thompson RW, Addy CL, Jones DA. The relationship between pedometer-determined ambulatory activity and body composition variables. Int J Obes Relat Metab Disord. 2001;25:1571-8.

24. Tudor-Locke C, Bassett DR, Swartz AM, Strath SJ, Parr BB, Reis JP, Dubose KD, Ainsworth BE. A preliminary study of one year of pedometer self-monitoring. Ann Behav Med. 2004;28:158-62.

25. Tudor-Locke C, Burkett L, Reis JP, Ainsworth BE, Macera CA, Wilson DK. How many days of pedometer monitoring predict weekly physical activity in adults? Prev Med. 2005;40:293-8.

26. Tudor-Locke C, Ham SA, Macera CA, Ainsworth BE, Kirtland KA, Reis JP, Kimsey CD, Jr. Descriptive epidemiology of pedometer-determined physical activity. Med Sci Sports Exerc. 2004;36:1567-73.

27. World Health Organisation. Obesity: preventing and managing the global epidemic. Report of a WHO consultation. Geneva: WHO Technical Report Series 894. 2000.

28. Wyatt HR, Peters JC, Reed GW, Barry M, Hill JO. A Colorado statewide survey of walking and its relation to excessive weight. Med Sci Sports Exerc. 2005;37:724-30. 
Table 1. Mean (SD) daily step counts and demographic characteristics of the two study groups, and for the sample as a whole.

\begin{tabular}{|c|c|c|c|c|}
\hline & $\begin{array}{l}\text { Reliability group } \\
\qquad(\mathrm{n}=162)\end{array}$ & $\begin{array}{l}\text { Confirmation group } \\
\qquad(\mathrm{n}=50)\end{array}$ & $\begin{array}{c}\text { Between } \\
\text { group }\end{array}$ & All $(n=212)$ \\
\hline & Mean (SD) & Mean (SD) & $\begin{array}{l}\text { differences } \\
\text { (p value) }\end{array}$ & Mean (SD) \\
\hline Age (years) & 38.6 (13.5) & $37.2(12.6)$ & 0.52 & $38.3(13.3)$ \\
\hline Height (cm) & $168.0(9.2)$ & $169.4(8.4)$ & 0.35 & $168.4(9.0)$ \\
\hline Weight (kg) & 79.1 (15.9) & 77.6 (19.8) & 0.57 & 78.8 (16.9) \\
\hline BMI $\left(\mathrm{kg} / \mathrm{m}^{2}\right)$ & $28.0(5.3)$ & $27.6(5.5)$ & 0.65 & $27.9(5.3)$ \\
\hline Mean steps/day & 9090 (2889) & 9826 (3365) & 0.13 & 9263 (3016) \\
\hline
\end{tabular}


Table 2. Mean (SD) daily step counts calculated on each day of the week for the reliability and confirmation groups, along with summary data for the sample as a whole.

\begin{tabular}{|c|c|c|c|c|}
\hline & $\begin{array}{l}\text { Reliability group } \\
\qquad(\mathrm{n}=162)\end{array}$ & $\begin{array}{l}\text { Confirmation group } \\
\qquad(\mathrm{n}=50)\end{array}$ & $\begin{array}{c}\text { Between } \\
\text { group }\end{array}$ & All $(n=212)$ \\
\hline & Mean (SD & Mean (SD) & $\begin{array}{c}\text { differences } \\
\text { (p value) }\end{array}$ & Mean (SD) \\
\hline Monday & $9280(3425)$ & 9886 (3620) & 0.28 & 9423 (3473) \\
\hline Tuesday & 9653 (3785) & 10230 (3885) & 0.35 & 9789 (3808) \\
\hline Wednesday & 9550 (3605) & 10774 (4129) & 0.06 & 9839 (3761) \\
\hline Thursday & 9113 (3262) & 9654 (4054) & 0.34 & 9241 (3462) \\
\hline Friday & 9512 (3392) & 9901 (3648) & 0.49 & 9604 (3449) \\
\hline Saturday & 8966 (3547) & 9980 (4798) & 0.11 & 9205 (3890) \\
\hline Sunday & 7555 (3528) & 8358 (4290) & 0.18 & 7744 (3727) \\
\hline Within group & & & & \\
\hline differences (p & $<0.001^{*}$ & $0.002 *$ & & $<0.001^{*}$ \\
\hline
\end{tabular}

* within group differences, mean daily step counts reported on a Sunday were significantly lower than those reported on all other days of the week in the two groups, and when the sample was analysed as a whole, following post hoc analyses (all $p<0.002$ ). 
Table 3. A summary of the ICC's calculated for different combinations of step count monitoring, ICC's were calculated using data from the reliability group $(\mathrm{n}=162)$.

\begin{tabular}{lcc}
\hline & \multicolumn{2}{c}{ Reliability } \\
& ICC & $95 \%$ CI \\
\hline Weeks 1-3 & 0.94 & $0.92-0.95$ \\
Weeks 1-2 & 0.92 & $0.90-0.94$ \\
Week 1 & 0.86 & $0.82-0.89$ \\
6 consecutive days & & \\
from week 1 & & \\
(7 combinations) & & \\
Mon - Sat & 0.84 & $0.80-0.88$ \\
Tues - Sun & 0.83 & $0.79-0.87$ \\
Wed - Mon & 0.83 & $0.79-0.87$ \\
Thurs - Tues & 0.84 & $0.79-0.87$ \\
Fri - Wed & 0.83 & $0.79-0.87$ \\
Sat - Thurs & 0.84 & $0.80-0.88$ \\
Sun - Fri & 0.84 & $0.80-0.88$ \\
Any 1 day & 0.41 & $0.36-0.47$ \\
\hline
\end{tabular}

